\title{
REAKTUALISASI PEMIKIRAN IBN QAYYIM AL-JAUZIYYAH DALAM PENGEMBANGAN TASAWUF
}

\section{Arikhah}

Fakultas Ushuluddin dan Humaniora Universitas Islam Negeri Walisongo Semarang Email : arikhab@gmail.com

\begin{abstract}
Sufism is considered as the cause of the destruction and bankruptcy of civilization. The presumption is based on the allegation that Sufism teaches thoughts of pantheism (doctrine that equates God with the forces and laws of the universe), cult (worship) on the human individual (including the trustee), drunkenness and insanity (ekstatisme/syațāhat), the story of suprarasional abilities, experiences that do not make sense and heresy, as well as other misguided thinking.

In the thought of Sufism, Ibn Qayyim called ijtihad implementation of Sufism by referring back to the al-Quran and al-Hadith, prioritize science than Sunnah worship, perform ijtihad that Sufism is not blind following to the masyayikh, do contextualization of Sufism appropriate time and place (Zaman wa eat) so understood Muslims all the time, do not isolate themselves from social life and make a series of Salik on the way to God (sair ilallah) not required sequence (tartib Gair mustahiqq), but optional (mustahsan).

Ibn Qayyim see Islam builds the concept of life departed from the faith, Islam and charity. Ibn Qayyim thinking about the meaning of the ascetic, more encouraging as the efforts for the improvement of human life, instill a positive attitude to the world and dare to face the reality of life and the challenges of advancement of age. In solitude, Ibn Qayyim requires a deep appreciation of esoteric religious but did not retreat from social life, but still actively involved in the community. The principles of balance (tawazun) are the laws for the entire universe. Therefore, Ibn Qayyim considers that violate the principle of balance is a cosmic sin, for breaking the law of Allah which controls the universe. Through remembrance, Ibn Qayyim explained that dhiker in complete sentences and meaningful then one more assured in terms of their faith because of a similar phrase that is active, confirmed the meaning and certain
\end{abstract}


attitudes are positive and good. In trust, Ibn Qayyim said closely related to the plans and efforts. If the plan is ripe, the results were submitted to Allah SWT.

Keywords: Ibn Qayyim, Tasawnf, ijtihad, al-Qur'an, al-Hadis

\begin{abstract}
Abstrak
Tasawuf dianggap sebagai penyebab kehancuran dan kebangkrutan peradaban. Anggapan tersebut didasarkan pada tuduhan bahwa tasawuf mengajarkan pemikiran-pemikiran pantheisme (ajaran yang menyamakan Tuhan dengan kekuatan-kekuatan dan hukum-hukum alam semesta), kultus (pemujaan) pada individu manusia (diantaranya kepada wall), kemabukan dan kegilaan (ekstatisme/syatähät), cerita tentang kemampuan-kemampuan suprarasional, pengalaman-pengalaman yang tidak masuk akal dan bid'ah, serta pemikiran sesat lainnya.
\end{abstract}

Dalam pemikiran tasawuf, Ibn Qayyim menyerukan ijtihad pelaksanaan tasawuf dengan merujuk kembali kepada al-Qur'an dan al-Hadis, memprioritaskan ilmu daripada ibadah sunnah, melakukan ijtihad agar ajaran tasawuf tidak taklid buta kepada para masyāyikh, melakukan kontekstualisasi ajaran tasawuf sesuai waktu dan tempat (zamān wa makān) agar difahami umat Muslim sepanjang waktu, tidak mengasingkan diri dari kehidupan sosial dan menjadikan rangkaian sälik dalam perjalanan menuju kepada Allah (sair ilälläh) tidak wajib berurutan (tartï gair mustahiqq), tetapi opsional (mustahsan).

Ibn Qayyim melihat Islam membangun konsep kehidupan bertolak dari iman, Islam dan ihsan. Pemikiran Ibn Qayyim tentang makna zuhud, lebih mendorong sebagai usaha-usaha untuk perbaikan hidup manusia, menanamkan sikap positif kepada dunia dan berani menghadapi kenyataan hidup dan tantangan kemajuan zaman. Dalam uzlah, Ibn Qayyim menghendaki suatu penghayatan keagamaan esoteris yang mendalam tetapi dengan tidak melakukan pengasingan diri dari kehidupan sosial, melainkan tetap aktif melibatkan diri dalam masyarakat. Prinsip-prinsip keseimbangan (tawā̌zun) merupakan sunnatulläh untuk seluruh jagad raya. Oleh karena itu, Ibn Qayyim menganggap bahwa melanggar prinsip keseimbangan merupakan suatu dosa kosmis, sebab melanggar hukum Allah SWT yang menguasai jagad raya. Melalui zikir, Ibn Qayyim menjelaskan bahwa zikir dalam kalimat lengkap dan 
bermakna maka seseorang lebih terjamin dari segi imannya karena kalimat serupa itu adalah aktif, menegaskan makna dan sikap tertentu yang positif dan baik. Dalam tawakal, Ibn Qayyim mengatakan erat kaitannya dengan rencana dan usaha. Apabila rencana sudah matang, hasilnya diserahkan kepada Allah SWT.

Kata kunci: Ibn Qayyim, Tasawuf, ijtihad, al-Qur'an, al-Hadis 


\section{A. Pendahuluan}

Upaya untuk mensinergikan penghayatan esoteris dan eksoteris selalu diperbaiki dengan gagasan purifikasi tasawuf untuk membawanya ke ranah kehidupan manusia yang lebih praktis, humanis dan solutif. Salah satu tokoh penting dalam hal ini adalah Abū 'Abd Allāh Syams ad-Dīn Muḥammad bin Abī Bakr bin Ayyūb bin Sa'd az-Zur'̄i ad-Dimasyqī Ibn Qayyim al-Jauziyyah (691-751 H/1292-1349 M) (az-Ziriklī, 2002, VI: 56), ${ }^{1}$ yang juga mendapat tempat di hati beberapa pemerhati tasawuf. ${ }^{2}$ Fazlur Rahman mengatakan bahwa al-Gazālī, Ibn Taymiyyah, termasuk juga Ibn Qayyim, dianggap sebagai tokoh pembaharu tasawuf (Rahman, 2003: 108-109).

Corak pemikiran Ibnu Qayyim banyak dipengaruhi oleh Ibn Taimiyyah yang mendasarkan pemikirannya pada al-Qur'an, al-Hadis dan mengesampingkan sumber-sumber lainnya. Ibn Qayyim mengajak dan menyeru kepada umat Islam untuk berijtihad dan meninggalkan taklid. Pengaruh ini kemudian lebih dikenal dengan salaf dan puritan. Meski pemikirannya dalam masalah ushul dan akidah sangat berpegang teguh pada mazhab Imam Ahmad Ibn Hanbal, namun dalam masalah furū' Ibn Qayyim punya pandangan yang independen.

Menurut Ibn Qayyim, segala amaliah yang tidak didasarkan pada alQur'an dan al-Hadis sangat tidak logis jika digunakan untuk mendekatkan diri kepada Allah di mana syari'at-Nya tidak dilaksanakan. Kesempurnaan manusia adalah dengan ilmu yang bermanfaat dan amal shalih, berupa petunjuk dan agama Islam, kesabaran dan saling mengingatkan dalam kebenaran. Hal

\footnotetext{
${ }^{1}$ Selanjutnya ditulis Ibn Qayyim. Nama populernya adalah Ibn Qayyim al-Jauziyyah, sedangkan penyebutan Ibn al-Qayyim sebagaimana dilakukan akhir-akhir ini adalah cara untuk meringkas nama Ibn Qayyim al-Jauziyyah (Abu Zaid, 1423: 27-28).

Beliau adalah ulama' ahli tasawuf dengan nama lengkap Abū 'Abd Allāh Syams ad-Dīn Muḥammad bin Abī Bakr bin Ayyūb bin Sa'ad bin Ḥāris̀ bin Makkī Zain ad-Dīn az-Zurīì adDimasyqī al-Ḥanbalī yang popular dengan sebutan Ibn Qayyim al-Jauziyyah. Nama al-Jauziyyah dinisbatkan kepada madrasah bernama al-Jauziyyah yang dibangun oleh Abūl Maḥāsin Yūsuf bin 'Abd ar-Raḥmān bin 'Alī al-Jauzī yang wafat pada tahun 656 H/1258 M di daerah pasar alBurūziyah di Damaskus. Ayahnya, Abū Bakr bin Ayyūb az-Zur'ī adalah salah seorang yang bertanggung jawab, pengurus dan tonggak (Qayyum) pada madrasah tersebut, maka disebutlah Ibn Qayyim (anaknya yang menjadi tonggak) (Ibn Hajar, 1972, I: 527 dan Ibn Kasìì, 1986, XIV: 234). Ia wafat pada tanggal 6 Safar 691 H/29 Januari 1292 M di Damaskus tepatnya di kampung Zur'ah dari perkampungan Haurān 55 mil sebelah tenggara Damaskus. Kelahirannya bertepatan dengan satu tahun setelah kemenangan kaum salib (al-Jauziyyah, 2001: 12). Ia dibesarkan dalam keluarga yang penuh dengan nuansa ilmu pengetahuan, ketaqwaan, kewara'an dan kedamaian.
} 
tersebut tentunya harus kembali kepada al-Qur'an, dengan memahami, menjelaskan dan mengambil mutiara yang terkandung di dalamnya (alJauziyyah, 2009: 27).

Sementara itu kalangan awam juga terjebak kepada kuantifikasi tasawuf. Dalam pelaksanaan suluk yang diajarkan kelompok tarekat seakan-akan memunculkan legalitas baru dalam Islam dan menjadikan tempat tumbuh suburnya takhayul, bidah dan khurafat. Selain itu, terjadi pula perpecahan dan pertentangan mazhab antara Ahlussunnah dan Syi'ah yang menimbulkan kekacauan, pertentangan dan pembunuhan di mana-mana, serta mengakibatkan lemahnya pemerintahan. Situasi semacam ini mengundang perhatian Ibn Qayyim untuk membangkitkan umat Islam dari tidur panjangnya dengan jalan memerangi taklid buta, khurafat, bidah dan kembali kepada alQur'an dan al-Hadis serta menghidupkan tauhid sebagai metodenya (Syaraf adDīn, 1984: 403-404).

Tasawuf yang tercampur taklid buta, khurafat dan bidah pada masa Ibn Qayyim yang dinilai menyimpang dari al-Qur'an dan al-Hadis seperti ittih̆äd (penyatuan Tuhan kepada makhluk-Nya) dan hulül (penyatuan makhluk kepada Tuhan) (al-Jauziyyah, 2009: 44-45; 792). Ittihäd disebut-sebut merupakan pemikiran tasawuf yang terpengaruh dari ajaran Yahudi, sedangkan hulül adalah terpengaruh dari ajaran Nasrani (As'ad-Saḥmarānī, 1987: 56-57). Dengan demikian, maka tasawuf yang seperti ini disebut sudah tidak murni lagi sebagai ajaran Islam, tetapi sudah terkontaminasi dengan ajaran lain sehingga dianggap keluar dari koridor Islam.

Metode Ibn Qayyim dalam menghidupkan kembali semangat tauhid ialah dengan mengajak kembali kepada sumber-sumber Islam yang suci dan murni, tidak terkotori oleh pendapat-pendapat abl al-abwä' wal bida '(ahli bidah) serta tipu daya orang-orang yang suka mempermainkan agama. Oleh sebab itulah Ibn Qayyim mengajak kembali kepada mazhab salaf aṣ-șälihịn (Ahsan, 1981: 169). Ibn Qayyim berusaha meletakkan iman, Islam dan ihsan dalam bingkai kesetaraan, keharmonisan dan sinergitas untuk mengantarkan umat manusia pada kebahagiaan hidup hakiki. Hal ini dilakukan dengan menciptakan kebahagiaan bagi orang lain yang sama dengan dirinya sejak berada dalam kehidupan di dunia sampai akhirat. Di samping itu, Ibn Qayyim juga menjadikan formulasi syari'at Islam sebagai ibadah yang penuh makna dan menjadi ruh kehidupan sehingga mampu merubah masyarakat Islam yang konseptual menjadi masyarakat Islam yang dinamis, hakiki dan nyata. 
Dalam kerangka ini, Ibn Qayyim tidak sejalan dengan pola pemikiran filsafat mutlak yang cenderung rasionalis yang amat berlebihan dalam menggunakan akal, Jahmiyyah, ittihădiyah, dialektika Yunani, dan zuhud India (Ahsan, 1981: 171; al-Jauziyyah, 2009: 1017). Ia ingin mengembalikan filsafat ke dalam bingkai Islam dengan cara mengikuti pendapat salaf aș-șälihin dan membersihkan Islam dari pemikiran-pemikiran yang keliru. Setelah itu, Ibn Qayyim menuntun umat Islam agar kembali kepada ajaran salaf ạ̦-șälihìn seperti yang terjadi pada masa awal Islam. $^{3}$ Dasar pemikiran tersebut dikategorikan ke dalam pemikir etika religius yang anti rasionalis (Fakhry, 1994: 151).

Secara umum, pemikiran sufistik Ibn Qayyim terdapat dalam kitab Madāìj as-Sälikin bain Manāzil Iyyäka Na'budu wa Iyyäka Nasta iñ. ${ }^{4}$ Sebagaimana judul kitabnya, substansi pemikiran sufistiknya bertumpu pada ayat al-Qur'an iyyäka na'budu wa iyyäka nasta'in, yang mengandung makna terdalam dari rahasiarahasia tentang penciptaan, segala perkara yang wujud, isi kitab-kitab, syari'at agama, pahala dan siksa yang menjadi inti dari ibadah dan tauhid. Makna yang sangat dalam dan berisi rahasia-rahasia terdalam tersebut mengandung dua pesan besar, yaitu untuk Allah berupa ibadah, ${ }^{5}$ dan untuk hamba itu sendiri berupa istianah. ${ }^{6}$

\footnotetext{
${ }^{3}$ Asy-Syaukānī bahkan menyebutnya sebagai pribadi yang sangat konsisten dan konsekuen dengan dalil yang shahih dan senang mengamalkannya, tidak memberikan peluang terhadap rasionalisme, berani berjuang demi kebenaran dan tidak pernah subyektif' (al-Jauziyyah, 1998: xx-xxvii).

${ }^{4}$ Pemikiran Ibn Qayyim tentang tasawuf tersebar di banyak buku yang ditulisnya, di

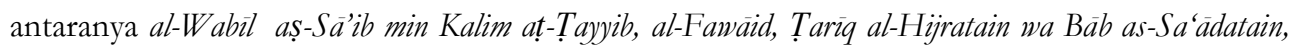
Iddāh aṣ- Säabirin, Raudah al-Muhibbin wa Nuz̧hat al-Musytāqīn, Tuhfah al-Maudūd bi Ahkeàm al-

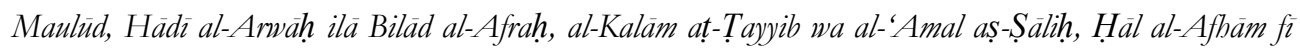
Żikr aș-Șaläh wa as-Saläm 'ala Khair al-Anäm. Namun pemikirannya dalam Madärij as-Sälikin bain Manāzil Iyyäka Na'budu wa Iyyäka Nasta'in lebih komprehensif daripada kitab lainnya. Hal ini dikarenakan Ibn Qayyim di dalamnya membahas beberapa persinggahan (manā̃ì), ahwāal (state) dan maqāmät (station) yang merupakan pendakian para sufi guna mencapai puncak pengetahuan terhadap Tuhan.

${ }^{5} \mathrm{Kata}-\mathrm{kata}$ ibadah berasal dari bahasa Arab 'abada-ya'budu-ibädatan-'ubüdiyyatan yang artinya beribadah, menyembah, mengabdi. Secara sempit ibadah sering dipahami sebagai melakukan perintah Allah yang sudah ditentukan kaifiah, syarat dan rukunnya sebagai kewajiban hamba. Dengan maksud ini ibadah terbatas pada yang disyariatkan Allah sebagaimana dalam rukun Islam. Meskipun secara luas yang dimaksud ibadah tidak hanya pada hal-hal yang diperintahkan Allah dengan ketentuan tertentu, melainkan segala perbuatan yang disukai dan menjadikan Allah ridla. Bandingkan dengan kitab Ibn Taimiyyah, al-Ubūdiyyah (2012)
} 


\section{B. Pemikiran Tasawuf Ibn Qayyim}

\section{Kritik Ibn Qayyim Terhadap Tasawuf}

Dari pengalaman perilaku para sufi di masanya, Ibn Qayyim melihat bahwa amaliah mereka banyak yang telah keluar dari wahyu yang dibawa Rasulullah. Hal ini dibuktikan dengan munculnya ragam tașanmuf falsafi yang dimulai oleh Abū Yazīd (w. 261 H/874 M) tentang ittihăd dan alHallāj (w. $301 \mathrm{H} / 913 \mathrm{M}$ ) tentang hulül yang kemudian berkembang dan tumbuh kembali pada Abad VI H dan setelahnya (at-Taftāzānī, 1979: 140). Tidak hanya itu, tasamwnf sunni yang terlalu ekstrim dalam prilaku dan konsep tasawufnya juga tidak lepas dari kritik Ibn Qayyim. Menurutnya, para penganut tașamnuf falsafi melakukan takwil yang jauh dari kebenaran al-Qur'an dan mengikuti cara-cara yang tidak sesuai dengan syari'at Islam. Sumber tersebut antara lain dari filsafat Neo-Platonis, Aristotelian, Persia dan lainnya sebagaimana konsep wahdah al-wujūd Ibn 'Arabi (w. 628 $\mathrm{H} / 1230 \mathrm{M})$.

Perilaku tasawuf seperti itu dinilai menggunakan opininya sendiri tanpa mengikuti kitab Allah dan sunnah rasul-Nya dengan menggunakan banyak perdebatan, kajian, analogi, masalah-masalah, simbol, syațahät dan berbagai khayalan yang lain. Sedangkan untuk tașawnuf sunni, Ibn Qayyim mengatakan bahwa mereka terlalu isräf (berlebihan) dan zalim (aniaya) tehadap diri sendiri dengan perilaku tasawufnya (ekstrim/guläh). (alJauziyyah, 2009: 26-27; asy-Syāṭibī, 1332 H; Rị̣ā, 1332 H). ${ }^{7}$

${ }^{6}$ Istianah adalah permohonan pertolongan kepada Allah didasarkan pada kepercayaan terhadap Allah dan penyandaran kepada-Nya. Hal ini merupakan sarana untuk dapat melaksanakan ibadah dengan lebih sempurna.

${ }^{7}$ Kritik Ibn Qayyim terhadap beberapa konsep tasawuf yang dianggapnya menyimpang mendapat berbagai tanggapan dari beberapa kritikus, diantaranya Maḥmūd Maḥmūd al- Gurāb dalm kitabnya, Syarh Kalimät aș-Süfiyyah wa ar-Radd 'alā Ibn Taimiyyah min Kaläm asy-Syaikh alAkbar Muhyì ad-Din Ibn al-'Arabi (1981). Al-Gurāb mengatakan bahwa Ibn Qayyim mengikuti kesalahan guru besarnya, Ibn Taimiyah, dalam mengkritisi para sufi, diantaranya Ibn 'Arabī. Pertama, kesalahan penafsiran. Menurut al-Gurābī (1981: 518-519) Ibn Qayyim banyak salah tafsir mengenai kalimat al-Harawī. Misalnya kalimat 'ain at-tanhìd dalam manzilab tafakekur. AlHarawī mengatakan bahwa tafakkur dalam 'ain at-tauhid adalah perbuatan sia-sia, sedangkan Ibn Qayyim mengatakan bahwa pernyataan al-Harawī kurang tepat karena hal tersebut malah mendekatkan diri kepada Allah. Di sini, Ibn Qayyim salah tafsir karena yang dimaksud alHarawī dengan 'ain at-tauhìd adalah Dzat Allah dimana Rasulullah melarang tafakur tentang Dzat-Nya, bukan tauhid itu sendiri sebagaimana difahami Ibn Qayyim. Kedua kesalahan metodologis. Pada manzilah tawakkul, Ibn Qayyim mengatakan bahwa orang Muslim maupun 
Segala amaliah yang tidak didasarkan pada al-Qur'an dan al-Hadis adalah tidak logis apabila digunakan untuk menuju kepada Allah yang mana syari'at Allah sendiri tidak dilaksanakan. Jalan menuju kepada kebaikan dan kebahagiaan adalah melalui petunjuk Allah, meningkatkan takwa dan berpegang teguh syari'at yang dibawa oleh Rasulullah saw. Di samping itu, kesempurnaan manusia adalah dengan ilmu yang bermanfaat dan amal shalih, berupa petunjuk dan agama Islam, kesabaran dan saling mengingatkan dalam kebenaran sebagaimana disebutkan dalam QS. al'Așr/103: 1-3. Jalan menuju Allah di atas tidak akan terwujud tanpa kembali kepada al-Qur'an, yaitu dengan memahami, menjelaskan dan mengambil mutiara yang terkandung di dalamnya (al-Jauziyyah, 2009: 27).

Kritik Ibn Qayyim terhadap penyimpangan para sufi antara lain sebagai berikut:

a. Pengetahuan tentang agama yang sedikit serta tidak tahu nama dan sifat Allah SWT. Para sufi banyak keluar dari konsep teologi seperti Jahmiyyah, abl an-nafy, abl at-ta'mil dan juga ajaran-ajaran yang lainnya.

b. Sibuk beribadah dan mendekatkan diri pada Allah daripada mendahulukan ilmu. Ibn Qayyim mendahulukan ilmu atas ibadah dan suluk dikarenakan ilmu lebih utama daripada salat sunnah dan ibadah lainnya. Ilmu mengantarkan kepada kebenaran dan untuk mengetahui

non-Muslim, penjahat dan pelaku dosa. Bahkan ia mengatakan bahwa tawakal non-Muslim, penjahat dan pelaku dosa lebih kuat daripada tawakalnya orang yang taat (al-Gurābī, 1981: 520). Ketiga kesalahan konseptual teoritis. Menurut al-Gurābī (1981: 363; 524-525) Ibn Qayyim melakukan kesalahan dalam mengkritik Ibn 'Arabi. Konsep manäz̧il al-Harawī dikembangkan lebih dahulu oleh Ibn 'Arabī dalam beberapa kitabnya seperti al-Futūhät al-Makkiyyah (lihat bab XXII yang menerangkan ilmu manzil al-manāąil dan urutan ilmu kosmis dalam Ibn 'Arabī, 1999, I: 262). Keterangan Ibn 'Arabī ini mendukung pernyataan al-Harawī dalam Manāżil as-Säiriñnya. Oleh karena itu, apa yang dijelaskan Ibn Qayyim bahwa ia mengikuti al-Harawi dan mengingkari Ibn 'Arabī adalah suatu keterputusan (discontinuity) dalam genealogi keilmuan.

${ }^{8}$ Dilihat dari kecenderungannya dalam menetapkan nama dan sifat Allah, Ibn Qayyim termasuk dalam abl al-išbät, yaitu mereka yang mengatakan bahwa Allah mempunyai zat dan juga mempunyai sifat sebagaimana diterangkan dalam al-Qur'an. Sedangkan abl an-nafy mengingkari adanya sifat bagi Allah. Bagi mereka, Allah adalah zat yang wajib wujud dan tidak mempunyai sifat. Lihat aș-Ṣifät al-Ilähiyyah fì al-Kitäb wa as-Sunnah an-Nabawiyyah fi Dau' al-Iśbät wa at-Tanž̄h karya Muḥammad Amān bin 'Alī Jāmī 'Alī (1408 H: 353)

${ }^{9}$ Abl at-ta'wil adalah mereka yang mempunyai kecenderungan untuk melakukan ta'wil (penafsiran makna ayat al-Qur'an, mengandung pengertian yang tersirat). Ibn Qayyim banyak mengkritik abl at-ta'wil karena tidak menafsirkan al-Qur'an sebagaimana metode para salaf aṣșälih dengan menyerahkan makna sepenuhnya kepada Allah (tafwiộl) sebagaimana dilakukan oleh Aḥmad bin Ḥanbal (yang kemudian disebut sebagai ablut tafwiẹ). Lihat 'Alī (1408 H: 12-13) 
mana yang baik dan mana yang tidak baik. Walaupun ibadah dan suluk bisa membersihkan hati, menyucikan jiwa, tetapi keduanya tetap membutuhkan ilmu untuk membedakan mana yang benar dan mana yang salah (al-Jauziyyah, 2009: 692-693; Syaraf ad-Dīn, 1984: 445448). ${ }^{10}$

c. Bersandar pada sumber selain al-Qur'an dan al-Hadis serta menjauh dari metode Rasulullah saw dan para sahabatnya. Menurut Ibn Qayyim, banyak sufi yang mengesampingkan sumber Islam dan metode Rasulullah dan para sahabatnya. Para sufi tersebut malah menggabungkan konsep tasawuf dengan konsep yang tidak sesuai dengan ajaran Islam, seperti konsep filsafat (wahdah al-wujūd), konsep Nasrani ( $h u l \bar{u})$, konsep Neo-Platonis, Persia, dan lainnya.

d. Mengikuti kesalahan para guru (masyayjikh). Para sufi yang ada pada masa Ibn Qayyim lebih banyak mengikuti masyäyikh mereka walaupun kadang mereka tidak benar dalam ajarannya. Misalnya adalah lebih sibuk beribadah daripada bersosialisasi dengan masyarakat, mengagungkan dan mengkultuskannya hingga menganggap bahwa masyäyikh adalah seorang yang terjaga dari dosa (ma'süm) (al-Jauziyyah, 2009: 155-156).

Dari kritik Ibn Qayyim di atas, maka tasawuf yang ingin didengungkan olehnya adalah tasawuf yang mengikuti jalan salafus șälihìn, bukan tasawuf yang dikonsepsikan oleh para sufi khalaf. Ibn Qayyim menyerukan ijtihad dalam bidang tasawuf dengan merujuk kembali kepada al-Qur'an dan al-Hadis. Ijtihad ini juga merupakan seruan untuk memerangi bidah dan khurafat kaum sufi yang berupa pengkultusan syaikh, melakukan sintesis ajaran Islam dan agama lain, memasukan tradisi filsafat dan faham-faham teologis yang menyimpang. Ibn Qayyim mengajak melakukan terobosan yang baru (update) ajaran tasawuf agar șälih li kulli zamān wa makān.

Konsep tasawuf Ibn Qayyim ada enam, yaitu kembali kepada alQur'an dan al-Hadis, memprioritaskan ilmu daripada ibadah sunnah,

${ }^{10} \mathrm{Al}-\mathrm{Gazāl} \bar{i}$ juga banyak membahas aspek kategorisasi ilmu ini dalam Ibyä’' Ulüm ad-Dìn (tt., I: 22) bahwa tasawuf harus berdasarkan dan mendahulukan pada ilmu, bukan sebaliknya. Hal ini terjadi ketika al-Muhāsibī mendoakan al-Sirrī al-Saqți: "ja alaka Allāh șạhiba hadìis șüfiyyan, wa là ja'alaka șüfiyyan șăhị hadìs." Ini menunjukkan bahwa orang yang mendapatkan ilmu dan hadis kemudian bertasawuf, maka ia akan beruntung, dan orang yang bertasawuf sebelum mengetahui ilmu, maka dirinya dikhawatirkan akan tersesat. 
melakukan ijtihad agar ajaran tasawuf tidak taklid kepada para masyajikh, melakukan kontekstualisasi ajaran tasawuf sesuai waktu dan tempat (zamān wa makān) agar difahami umat Muslim sepanjang waktu, tidak mengasingkan diri dari kehidupan sosial dan menjadikan rangkaian sälik dalam perjalanan menuju kepada Allah (sair ilä Alläh) tidak wajib berurutan (tartï gair mustahiqq), tetapi opsional (mustahsan).

\section{Dimensi Tasawuf Ibn Qayyim}

Dilihat dari kajian materinya, Ibn Qayyim membagi tasawuf menjadi dua dimensi, yaitu dimensi ibadah yang mencakup pada ketuhanan dan dimensi istianah yang mencakup pada kehambaan (al-Jauziyyah, 2009: 72). Dalam Tafsir al-Qayyim dijelaskan bahwa didahulukannya ibadah atas istianah (minta tolong) dalam surat al-Fatihah termasuk dalam bab mendahulukan ghäyāt (tujuan) atas wasäill (sarana). Karenanya, ibadah adalah tujuan hamba-hamba yang (memang) diciptakan untuknya. Sedang istianah (minta tolong) itu adalah wasilah (sarana) untuk ibadah (alJauziyyah, 1988: 66; 2009: 73).

Ibn Qayyim membagi kajian tasawufnya ke dalam tiga dimensi dilihat dari obyeknya, yaitu kepada Tuhan, manusia dan alam. Masingmasing akan dijelaskan sebagai berikut:

a. Dimensi Tuhan

Sebelum memulai perjalanan tasawuf, Ibn Qayyim menyebutkan bahwa masalah ketauhidan harus dipelajari dan dibenahi untuk pertama kalinya. Tauhid adalah maqām pertama yang harus didahulukan sebagaimana dakwah para utusan Allah dan juga hadis Rasulullah saw. ${ }^{11}$ Oleh karena itu, tidak sah maqämät maupun aḥwäl kecuali dengan tauhìd, di mana tauhid ini adalah kunci dakwah para utusan Allah (al-Jauziyyah, 2009: 112). Tauhid adalah hal pertama dalam Islam dan yang terakhir ketika manusia meninggal. Maka hal ini merupakan kewajiban awal sekaligus akhirnya dan awal perintah juga akhirnya (al-Jauziyyah, 2009: 1014).

Tauhid menurut Ibn Qayyim adalah mengesakan Allah dari para makhluk (ifräd al-Qadim 'an al-muhdasं) sebagaimana ia kutip dari pernyataan al-Junaid. Dengan definisi ini, maka pengakuan seseorang, maqām, hăal dan pengesaan hamba tidak sah kecuali dengan mengesakan

\footnotetext{
${ }^{11}$ Lihat juga hadis al-Bukhāri (2001, II: 104) nomor 1395 dan 1458 (2001, II: 119) dan Muslim (t.t, I: 51) hadis nomor 19.
} 
Allah dari para makhluk. Hal ini menafikan para sufi yang mengaku mengesakan Allah, tetapi konsep tasawufnya adalah ittihäd dan hulül serta para filosof, penyembah berhala yang menjadikan berhala sebagai perantara kepada Tuhan dan sebagainya (al-Jauziyyah, 2009: 1015).

b. Dimensi Manusia

Tugas dan kewajiban manusia adalah menyembah Allah. Allah telah menjadikan ibadah sebagai karakter makhluk-Nya yang paling sempurna dan dekat kepada-Nya. ${ }^{12}$ Di samping itu, Dia juga menjadikan kabar gembira bagi mereka yang menyembah-Nya. ${ }^{13}$ Tingkatan ibadah yang paling tinggi adalah ihsān, yaitu menyembah Allah seakan-akan tidak melihat-Nya dan jika tidak melihat-Nya, maka Dia melihatnya (al-Jauziyyah, 2009: 90-91). ${ }^{14}$

Kewajiban beribadah ini sama bagi semua manusia. Ibadah ini harus dilaksanakan hingga ajal menjemput dan wajib beribadah selama ia masih hidup. Siapapun yang mengaku telah sampai pada maqäm yang membebaskan dari beribadah, maka dia adalah orang yang zindiq dan kafir terhadap Allah dan rasul-Nya (al-Jauziyyah, 2009: 91-92).

Menurut Ibn Qayyim (al-Jauziyyah, 2009: 672), semua posisi manusia di hadapan Tuhannya sama. Yang membedakan hanyalah takwa dan hakikat iman itu sendiri, bukan kekayaan, jabatan, dan lainnya sebagaimana firman Allah dalam QS. al-Hujurāt/49: 13. Orang yang selamat dari siksa dan cobaan Allah adalah orang yang mengikuti petunjuk Allah, selalu menambah ketakwaannya, menempuh jalan yang lurus (șirät al-mustaqim), dan selalu mengikuti al-Qur'an dan al-Hadis (alJauziyyah, 2009: 27).

Takwa menurut Ibn Qayyim, sebagaimana dikutipnya dari Țalq bin Habīb (w.90 H/708 M) adalah amal dengan ketaatan kepada Allah atas cahaya-Nya, dengan mengharap pahala dan meninggalkan maksiat atas cahaya-Nya dengan takut kepada siksa-Nya. Unsur takwa tersebut tercakup dalam iman dan mengharap pahala dari Allah (ihtisäb). Orang

${ }^{12}$ Lihat QS. an-Nisā'/4: 172, al-A'rāf/7: 206, al-Anbiyā'/21: 19-20, al-Furqān/25: 63, alJinn/72: 16 dan al-Isrā'/17: 1. Lihat juga Șahịh al-Bukhārī hadis nomor 2462.

${ }^{13}$ Lihat QS. al-Zumar/39: 17-18, al-Zukhruf/43: 68-69, al-Hijr/15: 42 dan an-Naḥl/16: 99100.

${ }^{14}$ Ṣaḥịh al-Bukhārī hadis nomor 50.

Arikhah, Reaktualisasi Pemikiran Ibn Qayyim Al-Jauziyyah ... 
yang selalu berpegang teguh kepada ajaran Allah akan terjaga dari perbuatan bidah dan amal yang tidak baik (al-Jauziyyah, 2009: 326-327).

c. Dimensi Alam

Alam dengan segala isinya diperuntukkan untuk ciptaan Allah, baik yang beriman maupun yang tidak. Semua ciptaan Allah ini tidak sia-sia, semua dapat dimanfaatkan untuk kebutuhan makhluk-Nya. Namun Allah menjanjikan bahwa bagi orang-orang yang memanfaatkan alam dengan baik, maka hasilnya juga akan baik. Begitu juga sebaliknya. Oleh karena itu, prinsip pelestarian dan keseimbangan menjadi hukum Allah di dunia ini.

Alam, dengan segala bagiannya, menurut Ibn Qayyim mempunyai Sang Pembuat (Șäni), Sang Pencipta (Fạtir) dan Sang Pemilik (Malì). Maka orang yang mengingkari Sang Pembuat (Șāni ${ }^{\top}$, Sang Pencipta (Fätir) dan Sang Pemilik (Malik) menurut rasio dan fitrahnya adalah orang yang mengingkari wujudnya alam ini. Mengutip dari Ibn Taimiyyah, Ibn Qayyim mengatakan bahwa bagaimana seseorang mencari dalil atas keberadaan Allah sedangkan Dia adalah dalil atas segala sesuatu (kaifyutlabu ad-dalìl 'alà Man Huwa dalīl 'alà kulli syai'?) (alJauziyyah, 2009: 62-63). ${ }^{15}$

Lebih lanjut Ibn Qayyim mengatakan bahwa segala sesuatu yang terjadi di alam ini, baik kondisi, detail alam, jumlah galaksi dan bintang yang ada semuanya diketahui Allah (al-Jauziyyah, 2009: 68). Alam ini menuju proses kehancuran, sebagaimana alam adalah makhluk yang tentunya akan hancur ketika sudah sampai pada waktunya (al-Jauziyyah, 2009: 70).

Tujuan diciptakannya alam ini yang berasal dari perbuatan Allah adalah untuk kepentingan makhluk-Nya ('adlan wa hikmatan wa rahmatan wa ihsānan wa fadlan). Oleh karena itu, maka alam harus dijaga dan dilestarikan agar semuanya bersyukur. Dengan bersyukur, maka bertambahlah keberkahan alam dan menjadi lengkap nikmat yang diberikan Allah (al-Jauziyyah, 2009: 105; al-Gāmidī, 1420 H: 378).

Menjaga kelestarian alam dan menjadikannya warisan yang baik untuk masa depan makhluk yang lain adalah kewajiban makhluk-Nya. Caranya adalah dengan mengaplikasikan dan memanifestasikan nama

\footnotetext{
${ }^{15}$ Definisi alam atau makhluk menurut Ibn Qayyim adalah segala sesuatu selain Allah ( $m \bar{a}$ siwa Allāh) sebagaimana definisi para teolog Sunni pada umumnya.
} 
serta sifat Allah yang terpuji (Asmä al-Husnä) seperti penyayang (arRahim), lemah lembut (al-Halim), memberikan makanan bagi hewan dan tanaman (ar-Razzäq), menyediakan tempat bagi makhluk (al-Fattäh), reboisasi lingkungan (at-Tawwäb) dan lain sebagainya (al-Jauziyyah, 2009: 162, 315). Alam sebagai ladang dan tempat kehidupan harus dirawat dengan sebaik-baiknya agar memberikan yang baik bagi makhluk yang menghuninya dan jika tidak, maka yang terjadi adalah sebaliknya (al-Jauziyyah, 2009: 184).

\section{Reaktualisasi Pemikiran Tasawuf Ibn Qayyim}

Ibn Qayyim melihat Islam membangun konsep kehidupan bertolak dari iman, Islam dan ihsan. Tasawuf yang dikembangkan dalam kehidupan ini untuk memupuk keimanan, bukan untuk menggerusnya. Tasawuf yang demikian itu, dikembangkan dan dilembagakan melalui ajaran-ajaran sufi yang termanifestasi dalam ilmu pengetahuan. Sebagaimana yang terjadi pada masa kejayaan Islam, ilmu pengetahuan menghasilkan kreativitas dalam segala bidang kehidupan. Pada masa itu hampir semua pengembang dan penemu ilmu pengetahuan adalah orang-orang Islam.

Hal tersebut menyebabkan Ibn Qayyim sampai pada kesimpulan bahwa kreativitas di masa itu memang diupayakan, atau bahkan sistem pendidikan mengoptimalkan perkembangan kreativitas umat Islam. Untuk itulah dalam melakukan konstruksi pengetahuan yang berbasis tasawuf perlu penghayatan dan pemahaman serta pengalaman konsep dasar kehidupan dalam ajaran Islam yakni tentang iman, Islam dan ihsan.

Pemikiran Ibn Qayyim tentang makna zuhud, lebih mendorong sebagai usaha-usaha untuk perbaikan hidup manusia. Menanamkan sikap positif kepada dunia. Berani menghadapi kenyataan hidup dan tantangan kemajuan zaman. Sikap zuhud memotivasi manusia bagaimana menggunakan materimateri duniawi secara proporsional, tidak berlebih-lebihan, mendorong zähid menghindari perbuatan haram, hal-hal yang syubhat serta bersikap sederhana dalam hal-hal yang halal.

Karena bagi seorang zäbid, materi dan aktifitas duniawi dipandang sebagai sarana untuk meraih ridha Allah, mencapai kebahagiaan dunia dan akhirat. Dengan demikian, pemikiran zuhud sarat dengan motif moral (akhlak) dan menekankan bahwa seorang zahid harus aktif dan inklusif dalam realitas kehidupan sosial. 
Dalam uzlah, Ibn Qayyim menghendaki suatu penghayatan keagamaan esoteris yang mendalam tetapi dengan tidak melakukan pengasingan diri dari kehidupan sosial, melainkan tetap aktif melibatkan diri dalam masyarakat.

Untuk menjadi seorang sufi, seseorang tidak harus memasuki suatu tarekat, kemudian berhening-hening dengan guru (mursyid), tidak harus dengan menyepi ('uথlah) dan tidak harus dengan metode khusus dalam menempuhnya. Baginya ajaran tasawuf itu dapat dilakukan oleh siapa saja, dan kapan saja tanpa mengenal kekhususan. Karena tasawuf yang benar menurut Ibn Qayyim sebagaimana juga yang terdapat dalam kehidupan Rasulullah saw dan para sahabatnya.

Prinsip-prinsip keseimbangan (taw)äzun) merupakan sunnah Allāh untuk seluruh jagad raya. Oleh karena itu, Ibn Qayyim menganggap bahwa melanggar prinsip keseimbangan merupakan suatu dosa kosmis, sebab melanggar hukum Allah SWT yang menguasai jagad raya.

Dengan demikian, kehidupan spiritual Islam haruslah berjalan pada prinsip tawä̌un antara penghayatan esoteris dan penghayatan eksoteris. Barang siapa yang melanggar prinsip itu atau condong pada salah satu dari kedua prinsip saja berarti telah melanggar sunnah Alläh dan tentunya akan terjadi kepincangan dalam hidup keagamaannya.

Melalui zikir, Ibn Qayyim memberi penjelasan yang menarik. Beliau menjelaskan bahwa zikir dalam kalimat lengkap dan bermakna maka seseorang lebih terjamin dari segi imannya karena kalimat serupa itu adalah aktif, menegaskan makna dan sikap tertentu yang positif dan baik. Sedangkan zikir dengan lafal tunggal belumlah tentu demikian. Lingkungan makna dan semangat zikir kepada Allah SWT sangat luas sehingga meliputi semua aktifitas bukannya pasifis manusia yang membuatnya dekat kepada Allah SWT seperti mempelajari ilmu dan mengamalkan serta menjalankan amr al-ma'rüf dan naby al-munkar.

Dalam pandangan tasawuf Ibn Qayyim, tawakal erat kaitannya dengan rencana dan usaha. Apabila rencana sudah matang, hasilnya diserahkan kepada Allah SWT. Hanya Dia yang dapat mengetahui dengan pasti apa yang akan terjadi. Oleh karena itu, manusia harus menyerahkan kepada keputusan dan ketentuan Allah SWT.

Bagi kaum sufi, pengertian tawakkal itu tidak cukup hanya sekedar menyerahkan diri seperti itu, sebagaimana biasanya para sufi dalam mengartikan ajaran agama lebih jauh dan mendalam. Bagi kaum sufi dalam 
mengartikan tawakkal dengan menyerahkan secara total dan bulat segala sesuatunya kepada kekuasaan Allah SWT. Mereka tidak meminta, tidak menolak, tidak menduga-duga atas keputusan dan ketentuan Allah SWTT. Untuk itulah mereka menerima semua nasibnya itu dengan dipasrahkan pada kekuasaan Allah SWTT. Sikap seperti inilah yang dicari dan diusahakan oleh mereka, agar jiwa mereka tenang, berani, dan ikhlas dalam hidupnya walaupun apapun yang dihadapi atau dialami. 


\section{DAFTAR PUSTAKA}

'Abbās, 'Iwạ̣ Allāh Hamzah, 2013, Taqkiyah an-Nafs 'inda Ibn Qayyim alJauriyyah (691-751), Tesis Magister, Sudan: Universitas Islam Umm Dormān

'Asqalānī, Aḥmad bin 'Alī Ibn Hajar al-, 1972, ad-Durar al-Käminah fì A'yān alMi'ah às-Sáminah, India: Majlis Dā’irah al-Ma'ārif al-'U'smāniyyah, Cet. II

Abū Zaid, Bakr bin 'Abd Allāh, 1423 H, Ibn Qayyim al-Jauriyyah: Hayātubū Āं்̄rubū Mawāridubū, Riyadh: Dār al-'Āṣimah, Cet. II

Ahsan, Sayed, 1981, "Ibnu Qayyim al-Jauziyah," Islam and the Modern Age, 12(4), New Delhi: Zakir Husain Institut of Islamic Studies

'Alī, Muḥammad Amān bin 'Alī Jāmī, 1408 H, Șifät al-Ilāhiyyah fì al-Kitāb wa asSunnah an-Nabawiyyah fi Dau' al-İ́bāt wa at-Tanzīh, Madinah: al-Majlis al'Ilmī bi al-Jāmi'ah al-Islāmiyyah, Cet. I

Fakhry, Majid, 1994, Ethical Theories in Islam, Leiden: E.J. Brill, Cet. II

Gāmidī, Musfir bin Sa'īd al-, 1420 H, "al-Iḥsān: Ahammiyyatuhū, Aqsāmuhū, Śamrātuhū, Majallah al-Buhūis al-Islämiyyah, 58, 349-378

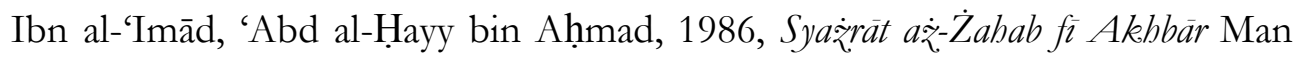

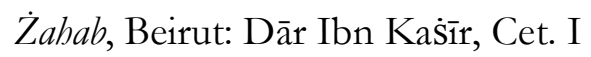

Ibn Taimiyya, 2012, al-'Ubüdiyyah, (ed. Abū 'Abd Allāh Muhammad bin Sa'īd bin Ruslān), al-Mansoura: Dār al-Gadd al-Jadīd

Jauziyyah, Muḥammad bin Abī Bakr Ibn Qayyim al-, 1998, Zäd al-Ma'àd, terj. Ahmad Sunarto dan Ainur Rofiq, Jakarta: Robbani Press ,2008a, Asmā' Allāh al-Husnā, (ed. M. Aḥmad 'Īsāa), al-Mansoura: Dār al-Gadd al-Jadīd, Cet. I

Mu'taṣim bi Allāh, Muḥammad al-, 2009, "Tarjamah Ibn Qayyim al-Jauziyyah Raḥimahū Allāh," dalam Muḥammad bin Ab̄̄ Bakr Ibn Qayyim alJauziyyah, Madārij as-Sālikin baina Manāzil Iyyāka Na'budu wa Iyyāka Nastaīn, (ed. M. al-Mu'tașim bi Allāh al-Bagdādī), Beirut: Dār al-Kitāb al'Arabī, 10-15 
Rahman, Fazlur, 2003, Revival and Reform in Islam: A Study of Islamic Fundamentalism, Oxford: Oneworld Publications

Rị̣ā, M uhammad Rasyīd, 1332 H, "Haqīqah at-Taṣawwuf wa Makānuhū fī asy-Syar'i," Majallah al-Manār, 161-185

Saḥmarānī, As‘ad, 1987, at-Taṣawwuf Mansya'ubū wa Muștalahăàtubu, Berut: Dār an-Nafā'is

Syaraf ad-Dīn, 'Abd al-'Az̄īm 'Abdussalām, 1984, Ibn al-Qayyim al-Jauziyyah: 'Așrubū wa Manhajubū wa Ārā'ubū fì al-Fiqh wa al-'Aqā'id wa at-Tașawnuf, Kuwait: Dār al-Qalam, Cet. III

Syātịib̄, Abū Isḥāq asy-, 1332 H, “al-Bāṭiniyyah wa Gulāh al-Mutaṣawwifah,” Majallah al-Manār, 273-293

Syaukān̄̄, Muḥammad bin 'Alī asy-, t.t, al-Badr aṭ-Ṭäli' bi Maḥāsin Man Ba'd alQarn as-Sābi', Beirut: Dār al-Ma'rifah

Taftāzānī, Abū al-Wafā al-Ganīmī at-, 1979, Madkhal ilā at-Taṣawnuf al-Islāmì, Kairo: Dāruś Ś aqāfah, Cet. III

Ziriklī, Khair ad-Dīn bin Mahmūd az-, 2002, al-A làm, t.tp: Dār al-'Ilm li alMalāyin, Cet. XII 